\title{
Corrigendum
}

\section{Corrigendum to "To Investigate the Effect of Colchicine in Prevention of Adhesions Caused by Serosal Damage in Rats"}

\author{
Ihsan Yıldız $\mathbb{D}^{1}{ }^{1}$ Yavuz Savas Koca $\mathbb{D}^{1},{ }^{1}$ Aziz Kemal Emek, ${ }^{2}$ and Tekinalp Gelen ${ }^{3}$ \\ ${ }^{1}$ Department of General Surgery, School of Medicine, Suleyman Demirel University, Isparta, Turkey \\ ${ }^{2}$ Department of General Surgery, School of Medicine, Akdeniz University, Antalya, Turkey \\ ${ }^{3}$ Department of Pathology, School of Medicine, Akdeniz University, Antalya, Turkey \\ Correspondence should be addressed to Ihsan Yıldiz; drihsanyildiz@gmail.com
}

Received 2 October 2018; Accepted 9 October 2018; Published 1 November 2018

Copyright (C) 2018 Ihsan Ylldiz et al. This is an open access article distributed under the Creative Commons Attribution License, which permits unrestricted use, distribution, and reproduction in any medium, provided the original work is properly cited.

In the article titled "To Investigate the Effect of Colchicine in Prevention of Adhesions Caused by Serosal Damage in Rats" [1], Drs. Aziz Kemal Emek and Tekinalp Gelen were missing from the authors' list. Dr. Aziz Kemal Emek's contribution is the study design, while Dr. Tekinalp Gelen's contribution is the examination of the pathology specimens of the research. The corrected authors' list and affiliations are shown above.

\section{References}

[1] I. Y1ldız and Y. S. Koca, "To investigate the effect of colchicine in prevention of adhesions caused by serosal damage in rats," Surgery Research and Practice, vol. 2015, Article ID 315325, 4 pages, 2015. 


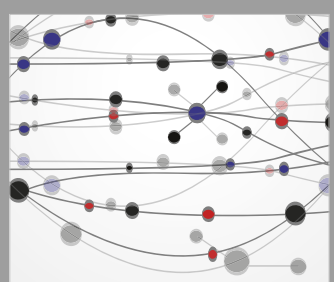

The Scientific World Journal
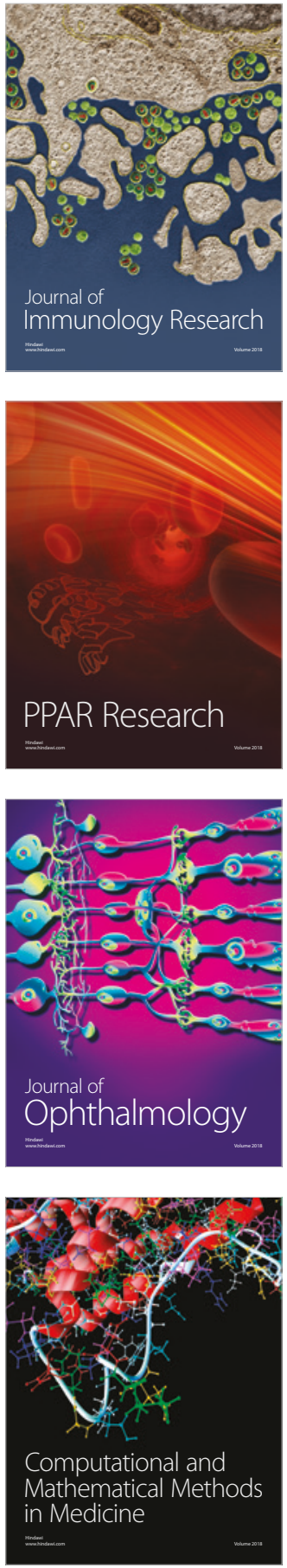

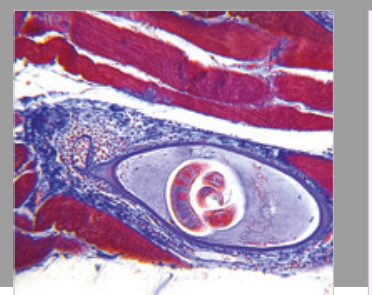

Gastroenterology Research and Practice

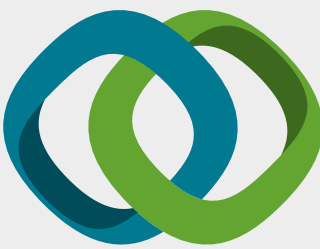

\section{Hindawi}

Submit your manuscripts at

www.hindawi.com
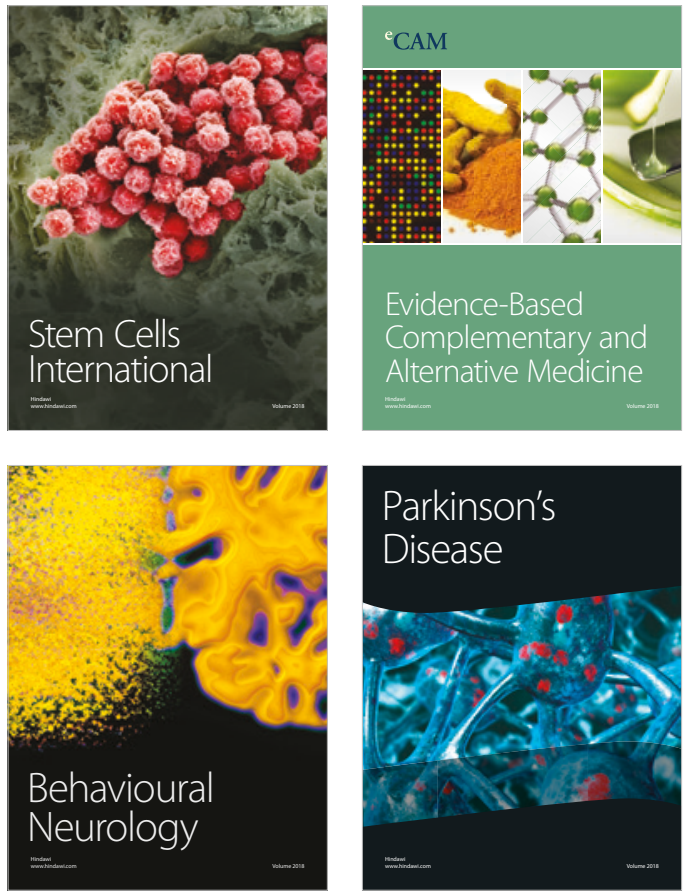

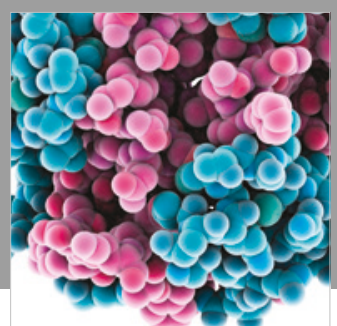

ournal of

Diabetes Research

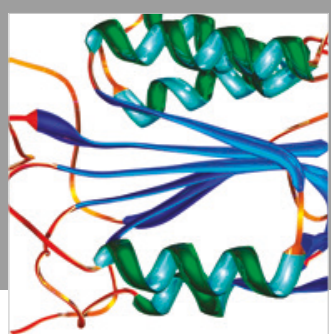

Disease Markers
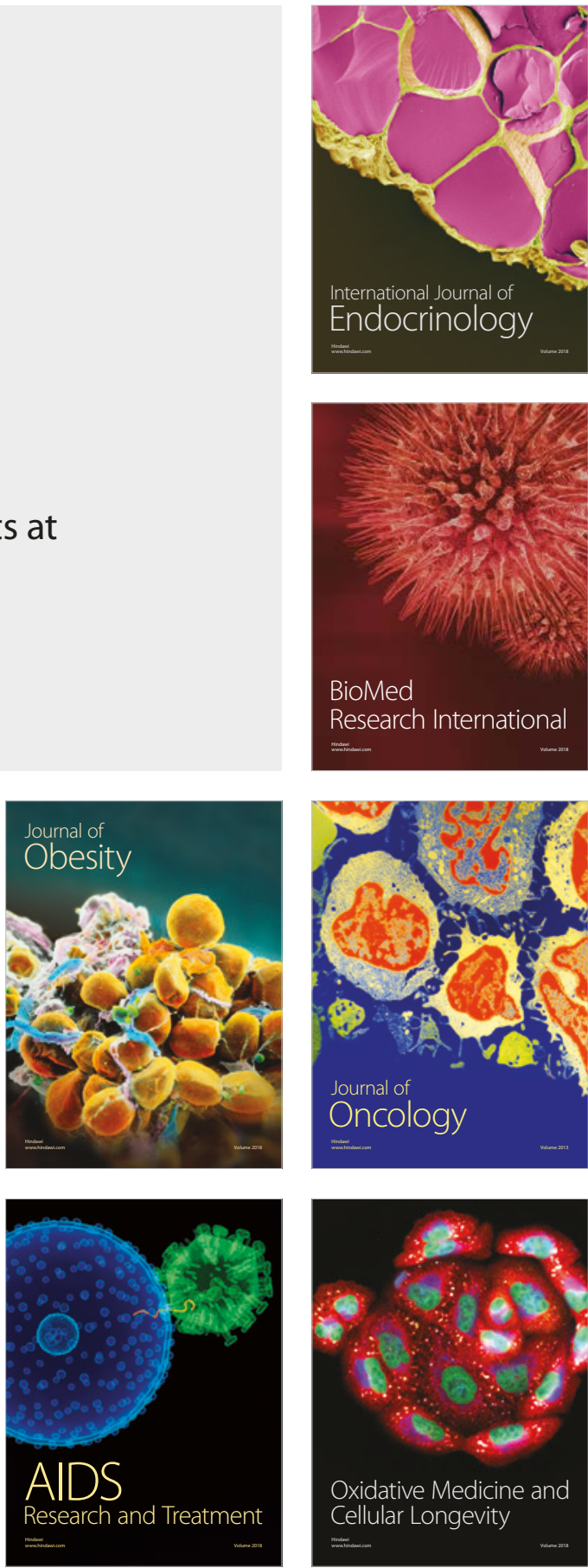